\title{
A health state assessment method for ship propulsion system based on fuzzy theory and variable weight theory
}

\author{
Pian Hu${ }^{1}$, Taotao Zhou ${ }^{2}$ \\ China Ship Development and Design Center, Wuhan, China \\ ${ }^{1}$ Corresponding author \\ E-mail: ${ }^{1}$ hupian701@163.com, ${ }^{2} \mathrm{kttktt@163.com}$ \\ Received 28 April 2017; accepted 29 April 2017 \\ DOI https://doi.org/10.21595/vp.2017.18561
}

Check for updates

\begin{abstract}
It is hard to determine the equipment weight in the ship propulsion system health status evaluation. A device weight determination method based on fuzzy theory and variable weight theory is presented. In this method, expert knowledge is used to determine the initial weight of each device; variable weights theory is used to appropriately adjust devices weights combining with the actual health status of each device. Simulation analysis results show that the proposed propulsion system integrated status assessment method could reasonably reflect actual status, which proves it to be scientific and valid in engineering application.
\end{abstract}

Keywords: fuzzy theory, variable weight theory, ship propulsion system, health status evaluation.

\section{Introduction}

The purpose of propulsion system health state assessment is to directly reflect the actual operating conditions of the system and provide supports for ship maintenance. In order to evaluate the health state of complex system which composed of a lot of equipment, it is necessary to divide the system according to the structure of the system, and then use an appropriate method to synthesize the its health state.

Ship propulsion is a typical complex system with complex hierarchical structure and diverse working conditions. At present, the grading evaluation [1,2], single-level fuzzy processing [3, 4] and multi-layer fuzzy technology $[5,6]$ have been studied for complex system health status evaluation [7]. Geng et al. [8] studied a ship system and equipment technology status evaluation method based on fuzzy model. From the perspective of engineering application, the ship is divided into equipment, subsystem, system and other levels, the fuzzy theory and weighted synthesis method are used to assess the propulsion device technical status. Abou et al. [9] solved fuzzy characteristics problem of the ship propulsion system condition monitoring parameters by using the fuzzy logic method and realized the ship propulsion system health state assessment. Li et al. [10] proposed an improved fuzzy health evaluation method using the degradation degree function, dynamic threshold and variable weight, and evaluated the degradation status of the wind turbine with the actual monitoring data. The results show that the improved method is accurate and reliable.

Aiming at the health status evaluation of propulsion system, the key problem is to determine each equipment weight coefficient scientifically and rationally. Current, the weight determining method is less, single subjective weighting method is usually used which with a strong subjectivity [11].

\section{Expert fuzzy scoring method and variable weight health assessment method}

\subsection{Expert fuzzy scoring method}

Considering the diversity and fuzziness of the propulsion system, the importance and the failure probability of equipment, each device weight coefficient is determined based on the expert fuzzy scoring method. In one condition, the propulsion system needs to start seven devices, the expert fuzzy score table is designed as shown in Table 1. 
Table 1. Expert fuzzy grading sheet

\begin{tabular}{|c|c|c|c|c|}
\hline Expert & Device 1 & Device 2 & $\ldots$ & Device 7 \\
\hline Expert I & 1 & 5 & $\ldots$ & 2 \\
\hline Expert II & 4 & 3 & $\ldots$ & 3 \\
\hline$\ldots$ & $\ldots$ & $\ldots$ & $\ldots$ & $\ldots$ \\
\hline Expert X & 5 & 2 & $\ldots$ & 2 \\
\hline
\end{tabular}

Assuming the influence of the health status of the equipment on the propulsion system status is divided into five levels showed by 1 to 5 . As shown in the Table 1, the expert I considers that the health state of the equipment 2 has a particularly large effect on the integrated state of the propulsion system, and its weight value is 5, and the health state of the device 1 has little effect on the propulsion system state, and its weight value is 1 . Here 10 experts give the device weight coefficient of the system.

Assuming that the influence of the $i$ th expert on the $j$ th device to the propulsion system health state is $\alpha_{i, j}$, where $\alpha_{i, j}$ is an integer of 1 to 5 . Then, the evaluation value of the $j$ th device in the advancing system is: $\lambda_{j}=\sum_{i=1}^{10} \alpha_{i, j}$, where $i=1,2, \ldots, 10$ which is the number of experts. Then, the weighting coefficients $b_{j}=\lambda_{j} / \sum_{j=1}^{7} \lambda_{j}$ are obtained by normalizing the score results, and the fuzzy weight value of the $j$ th device is obtained. The weighting coefficients of the device are obtained by $B=\left\{b_{1}, b_{2}, \ldots, b_{j}\right\}$, and the element $b_{j}$ is the weight coefficient of the $j$ th device.

\subsection{Variable weight health assessment method}

The initial weight of each device is determined by the subjective weighting method. The variable weight synthesis principle is used to consider the imbalance of assessment result, dynamically reflect the equipment health status, assess the propulsion system health state objectively and accurately.

According to the health status of each device, the variable value $C$ of the propulsion system health state is determined by:

$C=\sum_{j=1}^{m} 100 w_{j}\left(x_{1}, x_{2}, \ldots, x_{m}, \omega_{1}^{(0)}, \omega_{2}^{(0)}, \ldots, \omega_{m}^{(0)}\right) x_{j}$,

where $\omega_{m}^{(0)}$ is the initial weight of the device, and satisfies $\sum_{j=1}^{m} \omega_{j}^{(0)}=1 ; w_{j}$ is the variable weight of the device; $x_{j}$ is the state value of the $j$ th device.

Which:

$w_{j}\left(x_{1}, x_{2}, \ldots, x_{n}, \omega_{1}^{(0)}, \omega_{2}^{(0)}, \ldots, \omega_{n}^{(0)}\right)=\frac{\omega_{j}^{(0)} \frac{\partial B\left(x_{1}, x_{2}, \ldots, x_{n}\right)}{\partial x_{j}}}{\sum_{j=1}^{n} \omega_{k}^{(0)} \frac{\partial B\left(x_{1}, x_{2}, \ldots, x_{n}\right)}{\partial x_{k}}}$,

where $B\left(x_{1}, x_{2}, \ldots, x_{n}\right)$ represents the equilibrium function, that is, the gradient vector of the state variable weight vector $S(X)$.

The state variable weight vector is a very important factor in the variable weight evaluation. If the state variable weight vector is selected, the variable weight law is determined. According to the gradient vector of the literature, the empirical formula and the equilibrium function $B(X)=\sum_{j=1}^{m} x_{j}^{\alpha}(\alpha \in[0,1])$ are the most widely used variable weight vector. However, when the status of some devices is particularly small or even 0 , this time is not suitable for the use of empirical formula. Therefore, in order to consider the equilibrium relations among the factors, we choose the gradient vector of the equilibrium function $B(X)=\sum_{j=1}^{m} x_{j}^{\alpha}(\alpha \in[0,1])$ to construct 
the state variable weight vector.

From the Eq. (2) and $B(X)=\sum_{j=1}^{m} x_{j}^{\alpha}(\alpha \in[0,1])$ :

$w_{j}\left(x_{1}, x_{2}, \ldots, x_{n}, \omega_{1}^{(0)}, \omega_{2}^{(0)}, \ldots, \omega_{n}^{(0)}\right)=\frac{w_{j}^{(0)} x_{j}^{\alpha-1}}{\sum_{j=1}^{n} w_{k}^{(0)} x_{k}^{\alpha-1}}$.

Therefore, the health assessment of variable weight is:

$C=\sum_{j=1}^{m} \frac{w_{j}^{(0)} x_{j}^{\alpha}}{\sum_{j=1}^{n} w_{k}^{(0)} x_{k}^{\alpha-1}}$

In the health evaluation method, the variable weight principle is used to solve the problem that the health state of some equipment will affect the overall state of the whole system, and the evaluation result is more reliable and reasonable. The variable weight value reflects the equilibrium requirement, which affects the health evaluation result to a large extent. The practical application of a large number of engineering shows that $\alpha=0.2$ can be applied to general engineering situation.

\subsection{The method of weight determination combined expert fuzzy score with variable weight theory}

In order to ensure the safety of the system, assessing the system health state scientifically and reasonably, a weight determining method combined expert fuzzy score with variable weight theory is proposed. According to the equipment important degree in the propulsion system and the historical experience of the equipment failures, the initial weight coefficient of each device is determined, and the weight coefficient is adjusted according to the equipment health variable theory.

Compared with the conventional method, the variable weight synthesis method can highlight the serious defects of the equipment and avoid the serious damage of one or several of the equipment cannot be reflected in the health state assessment, affecting the accuracy of the assessment results. It will show the serious defects of the equipment in the propulsion system health evaluation and provide a more accurate and effective guidance for the using and maintenance of the propulsion system.

\section{Simulation analysis}

In order to illustrate the effectiveness of the proposed method, assume that the propulsion system consisted by six devices: gearbox, shaft, sliding bearing, propeller, oil pump, cooling water pump, fuel pump. According to the expert fuzzy scoring method, the score results of five industry experts are showed in Table 2.

Table 2. Expert fuzzy grading sheet

\begin{tabular}{|c|c|c|c|c|c|c|c|}
\hline Expert & Gears box & Propulsion shaft & Sliding bearing & Propeller & Oil pump & Cooling water pump & Fuel pump \\
\hline Expert 1 & 3 & 2 & 3 & 5 & 1 & 1 & 2 \\
\hline Expert 2 & 3 & 2 & 4 & 5 & 3 & 2 & 3 \\
\hline Expert 3 & 4 & 2 & 5 & 4 & 2 & 3 & 2 \\
\hline Expert 4 & 3 & 1 & 3 & 3 & 3 & 2 & 3 \\
\hline Expert 5 & 4 & 3 & 4 & 4 & 2 & 2 & 2 \\
\hline Total & 17 & 10 & 19 & 21 & 11 & 10 & 12 \\
\hline Weight & 0.17 & 0.10 & 0.19 & 0.21 & 0.11 & 0.10 & 0.12 \\
\hline
\end{tabular}


Consider the propulsion system is in the following five typical cases: 1) all equipment are in the optimal state; 2) all equipment are in a bad state; 3 ) all equipment are in a serious state of damage; 4) other equipment are in the normal state only sliding bearing is serious damaged; 5) Other equipment are in the normal state only oil pump is serious damaged. The validity of the health evaluation method is verified in Table 3, Table 4, Table 5, Table 6 and Table 7.

Table 3. Propulsion system health status evaluation sheet in condition 1

\begin{tabular}{|c|c|c|c|c|c|c|c|c|}
\hline Device & $\begin{array}{c}\text { Gears } \\
\text { box }\end{array}$ & $\begin{array}{c}\text { Propulsion } \\
\text { shaft }\end{array}$ & $\begin{array}{c}\text { Sliding } \\
\text { bearing }\end{array}$ & Propeller & $\begin{array}{c}\text { Oil } \\
\text { pump }\end{array}$ & $\begin{array}{c}\text { Cooling } \\
\text { water pump }\end{array}$ & $\begin{array}{c}\text { Fuel } \\
\text { pump }\end{array}$ & $\begin{array}{c}\text { Propulsion system } \\
\text { health status }\end{array}$ \\
\hline $\begin{array}{c}\text { Device } \\
\text { health status }\end{array}$ & 100 & 100 & 100 & 100 & 100 & 100 & 100 & 100 \\
\hline $\begin{array}{c}\text { Normal } \\
\text { weight }\end{array}$ & 0.17 & 0.10 & 0.19 & 0.21 & 0.11 & 0.10 & 0.12 & 100 \\
\hline $\begin{array}{c}\text { Variable } \\
\text { weight }\end{array}$ & 0.17 & 0.10 & 0.19 & 0.21 & 0.11 & 0.10 & 0.12 & \multicolumn{7}{c|}{ Note: All devices are in the optimal state } \\
\hline \multicolumn{8}{c|}{}
\end{tabular}

Table 4. Propulsion system health status evaluation sheet in condition 2

\begin{tabular}{|c|c|c|c|c|c|c|c|c|}
\hline Device & $\begin{array}{c}\text { Gears } \\
\text { box }\end{array}$ & $\begin{array}{c}\text { Propulsion } \\
\text { shaft }\end{array}$ & $\begin{array}{c}\text { Sliding } \\
\text { bearing }\end{array}$ & Propeller & $\begin{array}{c}\text { Oil } \\
\text { pump }\end{array}$ & $\begin{array}{c}\text { Cooling } \\
\text { water pump }\end{array}$ & $\begin{array}{c}\text { Fuel } \\
\text { pump }\end{array}$ & $\begin{array}{c}\text { Propulsion system } \\
\text { health status }\end{array}$ \\
\hline $\begin{array}{c}\text { Device } \\
\text { health status }\end{array}$ & 50 & 50 & 50 & 50 & 50 & 50 & 50 & \\
\hline $\begin{array}{c}\text { Normal } \\
\text { weight }\end{array}$ & 0.17 & 0.10 & 0.19 & 0.21 & 0.11 & 0.10 & 0.12 & 50 \\
\hline $\begin{array}{c}\text { Variable } \\
\text { weight }\end{array}$ & 0.17 & 0.10 & 0.19 & 0.21 & 0.11 & 0.10 & 0.12 & 50 \\
\hline \multicolumn{70}{|c|}{ Note: All devices are in bad condition } \\
\hline
\end{tabular}

Table 5. Propulsion system health status evaluation sheet in condition 3

\begin{tabular}{|c|c|c|c|c|c|c|c|c|}
\hline Device & $\begin{array}{c}\text { Gears } \\
\text { box }\end{array}$ & $\begin{array}{c}\text { Propulsion } \\
\text { shaft }\end{array}$ & $\begin{array}{c}\text { Sliding } \\
\text { bearing }\end{array}$ & Propeller & $\begin{array}{c}\text { Oil } \\
\text { pump }\end{array}$ & $\begin{array}{c}\text { Cooling } \\
\text { water pump }\end{array}$ & $\begin{array}{c}\text { Fuel } \\
\text { pump }\end{array}$ & $\begin{array}{c}\text { Propulsion system } \\
\text { health status }\end{array}$ \\
\hline $\begin{array}{c}\text { Device } \\
\text { health status }\end{array}$ & 0 & 0 & 0 & 0 & 0 & 0 & 0 & 0 \\
\hline $\begin{array}{c}\text { Normal } \\
\text { weight }\end{array}$ & 0.17 & 0.10 & 0.19 & 0.21 & 0.11 & 0.10 & 0.12 & 0 \\
\hline $\begin{array}{c}\text { Variable } \\
\text { weight }\end{array}$ & 0.17 & 0.10 & 0.19 & 0.21 & 0.11 & 0.10 & 0.12 & 0 \\
\hline \multicolumn{7}{|c|}{ Note: All equipment is severely damaged } \\
\hline
\end{tabular}

Table 6. Propulsion system health status evaluation sheet in condition 4

\begin{tabular}{|c|c|c|c|c|c|c|c|c|}
\hline Device & $\begin{array}{c}\text { Gears } \\
\text { box }\end{array}$ & $\begin{array}{c}\text { Propulsion } \\
\text { shaft }\end{array}$ & $\begin{array}{c}\text { Sliding } \\
\text { bearing }\end{array}$ & Propeller & $\begin{array}{c}\text { Oil } \\
\text { pump }\end{array}$ & $\begin{array}{c}\text { Cooling } \\
\text { water pump }\end{array}$ & $\begin{array}{c}\text { Fuel } \\
\text { pump }\end{array}$ & $\begin{array}{c}\text { Propulsion system } \\
\text { health status }\end{array}$ \\
\hline $\begin{array}{c}\text { Device } \\
\text { health status }\end{array}$ & 90 & 90 & 10 & 90 & 90 & 90 & 90 & \\
\hline $\begin{array}{c}\text { Normal } \\
\text { weight }\end{array}$ & 0.17 & 0.10 & 0.19 & 0.21 & 0.11 & 0.10 & 0.12 & 74.80 \\
\hline $\begin{array}{c}\text { Variable } \\
\text { weight }\end{array}$ & 0.10 & 0.05 & 0.63 & 0.12 & 0.03 & 0.03 & 0.04 & 39.28 \\
\hline \multicolumn{8}{|c|}{ Note: The sliding bearing has been severely damaged } \\
\hline
\end{tabular}

It can be concluded from Table 3, Table 4 and Table 5 that the results of the variable weight method are the same as those obtained by the health assessment method when the health status of all the equipment is consistent. It indicates that the two methods can effectively reflect the actual state of the propulsion system.

Observe Table 6, the other equipment is in the normal state only sliding bearing serious 
damage, you can find, often the weight of the health assessment of the results of 74.80 , said the propulsion system is in a normal state; the proposed health assessment method to assess the results of 39.28 , show the propulsion system is in a bad state. And then observe the Table 7, the other equipment is in the normal state only a serious damage to the case of oil pump, you can see, often the weight of the health assessment of the results of 80.40, said the propulsion system in a normal state; proposed health assessment method to assess the results of 63.18 , Indicating that the propulsion system is in a bad state. In both cases, there is a serious damage to the equipment; we need to carry out maintenance. The results of the conventional method cannot show the propulsion system actual state obviously, and the proposed evaluation method can effectively assess the actual state of the propulsion system and can provide the health evaluation value of the ship allegation system according to the actual situation.

Table 7. Propulsion system health status evaluation sheet in condition 5

\begin{tabular}{|c|c|c|c|c|c|c|c|c|}
\hline Device & $\begin{array}{c}\text { Gears } \\
\text { box }\end{array}$ & $\begin{array}{c}\text { Propulsion } \\
\text { shaft }\end{array}$ & $\begin{array}{c}\text { Sliding } \\
\text { bearing }\end{array}$ & Propeller & $\begin{array}{c}\text { Oil } \\
\text { pump }\end{array}$ & $\begin{array}{c}\text { Cooling } \\
\text { water pump }\end{array}$ & $\begin{array}{c}\text { Fuel } \\
\text { pump }\end{array}$ & $\begin{array}{c}\text { Propulsion system } \\
\text { health status }\end{array}$ \\
\hline $\begin{array}{c}\text { Device } \\
\text { health status }\end{array}$ & 90 & 90 & 90 & 90 & 90 & 90 & 10 & \\
\hline $\begin{array}{c}\text { Normal } \\
\text { weight }\end{array}$ & 0.17 & 0.10 & 0.19 & 0.21 & 0.11 & 0.10 & 0.12 & 80.40 \\
\hline $\begin{array}{c}\text { Variable } \\
\text { weight }\end{array}$ & 0.14 & 0.08 & 0.17 & 0.18 & 0.05 & 0.04 & 0.34 & 63.18 \\
\hline \multicolumn{8}{|c|}{ Note: The fuel pump has been severely damaged } \\
\hline
\end{tabular}

In the case of sliding bearings or fuel pumps of the propulsion system is severely damaged, compare the results of the two health state assessment methods, we can find that the health status results of the propulsion system by conventional method to are normal and required on maintenance. The results by the proposed method are in bad state and need maintenance. It can be found that the conventional method ignores the failure in the system and cannot reflect correctly the propulsion system state. The proposed health assessment method can effectively characterize the actual state of the propulsion system.

\section{Conclusions}

In order to determining the equipment weight of the propulsion system, a weight determination method combining fuzzy theory and variable weight theory is proposed. This method uses the expert knowledge to determine the initial weight of equipment according to the importance and the historical operation experience of the equipment. On this basis, combined with the actual health status of equipment, the weights are adjusted appropriately by the variable weight theory, which could reflect the system's actual state more reasonable. The simulation results showed that the proposed method could reflect actual status of propulsion system reasonably and effectively.

\section{References}

[1] Barger T. S., Brown D. E., Alwan M. Health-status monitoring through analysis of behavioral patterns. IEEE Transactions on Systems, Man, and Cybernetics - Part A: Systems and Humans, Vol. 35, Issue 1, 2005, p. 22-27.

[2] Miao Q., Wang D., Pecht M. A probabilistic description scheme for rotating machinery health evaluation. Journal of Mechanical Science and Technology, Vol. 24, Issue 12, 2010, p. 2421-2430.

[3] Sohn H., Farrar C. R., Hemez F. M., et al. A Review of Structural Health Monitoring Literature: 1996-2001. Los Alamos National Laboratory, 2003.

[4] Shen C., Wang D., Kong F., et al. Fault diagnosis of rotating machinery based on the statistical parameters of wavelet packet paving and a generic support vector regressive classifier. Measurement, Vol. 46, Issue 4, 2013, p. 1551-1564. 
[5] Yan R., Gao R. X. An efficient approach to machine health diagnosis based on harmonic wavelet packet transform. Robotics and Computer-Integrated Manufacturing, Vol. 21, Issue 4, 2005, p. 291-301.

[6] Zeng S., Pecht M. G., Wu J. Status and perspectives of prognostics and health management technologies. ACTA Aeronautica et Astronautica Sinica - Series A and B, Vol. 26, Issue 5, 2005, p. 626-632.

[7] Widodo A., Yang B. S. Support vector machine in machine condition monitoring and fault diagnosis. Mechanical Systems and Signal Processing, Vol. 21, 2007, p. 2560-2574.

[8] Geng J. B. Research on Technical Condition Integrated Evaluation for Power Plant of Ships Based on Information Fusion. Huazhong University of Science and Technology, 2007.

[9] Abou S. C., Stachowicz M. Ship propulsion system health monitoring based on safety control functions. ELMAR, 50th International Symposium, Vol. 2, 2008, p. 393-396.

[10] Li H., Hu Y. G., Yang C., et al. An improved fuzzy synthetic condition assessment of a wind turbine generator system. International Journal of Electrical Power and Energy Systems, Vol. 45, Issue 1, 2013, p. 468-476.

[11] Liang S. T., Hao C. X., Wang M. L. The application of fuzzy neural network in the marine electric propulsion system condition assessment. Chinese Journal of Ship Research, Vol. 9, Issue 5, 2014, p. $99-104$. 